\title{
A Contrastive Study of Hedging in Environmental Sciences Research Articles
}

\author{
Alireza Bonyadi \\ Department of English, Islamic Azad University, Urmia Branch, Urmia, Iran \\ Email: bonyadi.alireza@yahoo.com \\ Javad Gholami \\ Department of English, Urmia University, Urmia, Iran \\ Email: j.gholami@urmia.ac.ir \\ Sina Nasiri \\ Department of English, Islamic Azad University, Urmia Branch, Urmia, Iran \\ Email: sina.nasiri.86@gmail.com
}

\begin{abstract}
Academic writers resort to hedging as one of the interpersonal metadiscourse category not only to present their findings cautiously but also to minimize the effects of Face Threatening Acts (FTAs). The purpose of the present study was to compare and contrast the frequency and types of hedges in Discussion sections of Environmental Sciences Research Articles (RAs) written by English Research Writers (ERWs), Iranian Research Writers (IRWs) who write in English, and Iranian Research Writers (IRWs) who write in Farsi. To this end, 60 RAs in the targeted field were selected from leading journals (20 for each group), and then the used hedges were analyzed based on Salager-Meyer (1994) taxonomy. With regard to the use of hedges in English, this study did not find any significant differences between English and Iranian authors' writings. However, the findings revealed significant differences between English and Farsi written articles. This discrepancy can be attributed to the nature of Farsi language which might consider less hedged texts as highly validated ones. However, this is opposed to the credibility of using hedges in this field in the international academic discourse community.
\end{abstract}

Index Terms-hedges, discussion section, RAs, ERWs, IRWs

\section{INTRODUCTION}

Writing is one of the channels of communication and academic writing, as one of the forms of written discourse, involves interpersonal relationship between author and addressees in an academic discourse governed by certain conventions. Academic writing is created by paying special attention to the specific constraints or conventions of a discipline. Theses conventions might ensure academic writers that their work is recognized by readers and accepted by their colleagues in their discourse community.

Therefore, in academic writing writers try to either fill a certain knowledge gap or add new information to the existing literature in a way which is consistent with the expectations of the particular community they belong to. To do so, they present their finings in Research Articles (RAs).

In other words, in writing RA for particular community and specific discipline, in addition to presenting propositional contents, authors should consider their audience and their background knowledge in the subject matter (Widdowson, 1984; Hyland, 2004). It fact a conscious awareness of the rules and conventions governing academic communication is a prerequisite for effective writing and processing of academic discourse. In line with this matter, Hyland (1999) asserts that features of discourse are always relative to a specific audience and social purposes, and the effectiveness of writers' attempts to communication relies on how much they are successful in analyzing and accommodating the needs of readers.

According to Hyland (2004) one of the important ways of representing the features of an underlying community is through the writer's use of metadisourse. Metadiscourse has been defined as writing about writing (Williams, 1981), discourse about discourse, or communication about communication (Vande Kopple, 1985). Mauranen (1993) refers to metadisourse as certain elements in the text that go beyond the propositional content.

Hyland (1998) also states that, metadiscourse dose not add to the propositional content of a text but guides or direct readers to how they should understand and evaluate that content. Crismore (1984) takes the similar stance and believes that the aim of metadiscourse is to "direct rather than inform the readers" (p. 280).

There are two main categories for metadiscourse; textual and interpersonal (Vande Kopple, 1985, 2002; Hyland, 1998; Crismore, Markkanen \& Steffensen, 1993). While the former helps writers incorporate ideational materials within a text in a way which makes sense in a particular situation for readers, the later one assists writers to represent their 
opinions and their evaluations of situation they are involved and shows how they hope readers will react on the ideational material (Vande Kopple, 2002). Metadiscourse can be classified through different subcategories, such as logical connectives, code glosses, emphatics, and hedges.

The focus of this study is on hedges (or hedging strategy) as a subcategory of interpersonal metadisourse. Studying hedges from an interpersonal perspective, Hyland (1996) believes that the interpersonal metadiscourse is to do with respecting the institutional constraints and expectations of the scientific community. Nikula (1997) contends that hedges are communicative strategies which enable writers soften the force of their utterances to make them more acceptable in interpersonal relationships.

As Varttala (2001) states, much of previous work on the interpersonal aspect of hedging has been based on Politeness Theory proposed by Brown and Levinson $(1978,1987)$. Politeness means that "behaving or speaking in a way that is correct for the social situations you are in, and showing that you are careful to consider other people's needs and feelings" (Longman Dictionary, 2006). Brown and Levinson's (1987) theory is based on the existence of participants who have something that is called Face which could be interpreted as a public self-image. They divide the term face into positive and negative ones. Positive face refers to a positive self image, a desire that self image is appreciated and approved of by others, while negative face refers a desire to have a freedom of action and rights to non-distraction (Brown \& Levinson, 1987).

Myers (1989) argues that in academic discourse making claims threatens the negative face of other researchers; since it restricts the freedom of the other researchers in choosing how to act upon the claims and interpret them with their own reasons. In other words, if the authors do not leave room for the readers to have their freedom of action and claim their findings with high degree of certainty, they invade the readers' realm and force them to accept what they claim, and accordingly threaten the negative face of them.

As a result, the use of hedges as one of the negative politeness strategies in addition to their interpersonal function is the necessity for mitigateing Face Threatening Acts (FTAs) involved in the social interactions between writers and readers.

Hedging as an interesting linguistic category, however, is extremely difficult to be defined. Over the years hedge and hedging have been viewed from different angles by different researchers. As a result, no common description exists about hedge and hedging in the literature (Varttala, 2001). As Hyland (1998) states, direct definition of the notions are scarce and the existing ones are used differently by different authors.

Considering the current different definitions of hedges, it is not surprising that studies of hedging are initiated with a definition of the term in a certain study. Likewise the adopted definition in this study is based on Salager-Meyer, Defives and Hamelynck's (1996) definition which consists of five dimensional concepts. They define hedging as rhetoric, semantic and pragmatic devices used in the scientific communication among specialists for:

1. Creating purposive fuzziness and vagueness (threat-minimizing strategy);

2. Reducing levels of certainty of the truth of propositions (i.e. impossibility or unwillingness of reaching absolute accuracy and of quantifying all the phenomena under observation);

3. Expressing tentativeness and flexibility;

4. Projecting modesty for achievements and politeness with the community;

5. Avoiding personal involvement.

As in the academic world there is always a sense of "uncertainties, indirectness, and non-finality" (Mauranen, 1997, p.115), academic writers and particularly RA writers need to present their claims cautiously, tentatively, diplomatically, and modestly in order to meet the expectations of the corresponding discourse community (Hyland, 1995; SalagerMeyer, 1997). For instance, instead of writing "pickles are vegetables" it would be better for the writers to put it in cautious way and write "pickles can be viewed as vegetables" (Varttalla, 2001, p. 9).

Research article authors' degree of commitment to their claims and accordingly showing their respect and politeness to their colleagues at the same time is one of the issues which has occupied the minds of researchers in the field of discourse analysis. For instance, Salager-Meyer (1994) analyzed fifteen English medical articles and identified the frequency of hedges based on her category (i.e., shields, approximators, authors' personal doubt, emotionally-charged intensifiers, and compound hedges) within two genres of written discourse; namely, case report (CR) and research paper (RP). Her research results revealed high frequency of occurrence of hedges such as shields, approximators, and compound hedges in the sample. Her study also showed that the Discussion sections in the RP and Comment section (i.e. Discussion section) contained the most hedges whereas the Methods sections were the least-hedged rhetorical sections. Salager-Meyer believed that the use of hedges is related to the general structure of the discourse community. It can be concluded that the conventions of the discourse community and obeying the rules by the researchers determined the use of hedges in this study.

Falahati (2004) investigated hedges in Introduction and Discussion sections of medicine, chemistry, and psychology RAs in two languages; English and Farsi. The findings of this study showed that the English RAs were more hedged than the Farsi RAs. The results also showed that the Discussion sections of RAs, in general, favor more hedges than the Introduction sections. The distribution of hedging devices was shown to be different across disciplines. The English psychology and Farsi medicine RAs were found to be the most heavily hedged disciplines. It can be stated that English 
language as a dominant language in today's scientific world needs more hedges from the researchers, since the community is consisted of members from the whole world.

Yang (2006), focusing on a corpus of 10 texts in material science discipline, explored the use of hedging both by Chinese and English writers. The results of this study showed that RAs written by Chinese writers tend to be more direct and authoritative in tone which may be related to the nature of the language in that particular discipline.

Martin (2008) in his study analyzed hedges in English and Spanish written RAs in Clinical and Health Psychology disciplines. The results of his study revealed that there are similarities between the two languages regarding the distribution of hedges across the different sections of the RAs, although a certain degree of indetermination strategy occurs in English texts and showing English RAs in the field of Clinical and Health Psychology provide more protection to the author's face. What is gained is that nationality is less powerful than the discipline in affecting the writing style.

Jalilifar (2011) examined 90 research article Discussion sections' hedges and boosters in two disciplines of Applied Linguistics and Psychology by three groups of writers; English writer, Perlish (Iranian writers write in English), and Persian writers (Iranian writers write in Farsi). The results of analyses showed significant differences in frequency, type, and functions of these devices in the texts. Jalilifar claimed that differences might be attributed to lack of awareness of the conventional rules of English rhetoric, limited knowledge of academic English by Persian writers, and lack of explicit instruction and exposure to pragmatic and sociolinguistic rules of English by Persian researchers. It seems that Iranians researchers should be thought enough about the role of hedges in the academic community.

In spite of recent studies on hedges (e.g. Crompton, 1997; Kreutz \& Harres, 1997; Namsarayer, 1997; Salager-Meyer, 1994, 1997; Wishnoff, 2000; Varttala, 2001; Hyland, 2000; Atai \& Sadr, 2008; Winardi, 2009), the study of hedging has only just begun and is relatively new in discourse studies (Hyland, 2009).

To the best knowledge of the researchers of this study, the study of hedges in the field of Environmental Sciences has been neglected in the literature. Moreover, studies on hedges have been conducted in Iran are based only on interactional perspective. However, the present study has tried to look at the hedges from the concept of politeness perspective to enrich the literature. Specifically, the purpose of the present study is to compare and contrast the frequency and types of hedges used in Environmental Sciences RAs written by three groups of writers: English Research Writers (ERWs), Iranian research Writers (IRWs) (writing in English), and Iranians who write in Farsi.

Regarding what we mentioned in the previous sections and based on the purposes, the present paper seeks to answer the following research questions:

1. Is there any significant difference between English Environmental Sciences RAs written by English Research Writers and Iranian Research Writers in terms of the number and types of hedges used in their Discussion sections?

2. Is there any significant difference between English and Farsi Environmental Sciences RAs written by English Research Writers and Iranian Research Writers in terms of the number and types of hedges used in their Discussion sections?

3. Is there any significant difference between English and Farsi Environmental Sciences RAs written by Iranian Research Writers in terms of the number and types of hedges used in their Discussion sections?

\section{METHODOLOGY}

\section{Corpus}

The corpus of this study was based on a set of English and Farsi data composed of 60 research articles of Environmental Sciences discipline from 2005-2009; 20 English articles written by EWRs, 20 English articles written by IRWs, and 20 Farsi articles written by IRWs. Articles by EWRs were taken from the leading journal, American Journal of Environmental Sciences, and articles by IRWs in both English and Farsi were taken from the leading journals in Iran, namely Environmental Sciences, International Journal of Environmental Sciences, and International Journal of Environmental Sciences and Technology.

\section{Procedure}

After selecting the articles, the Discussion sections of them were analyzed for the frequency and types of hedges used by the writers. The Discussion section was chosen for this study, since it is the most heavily hedged section due to the kind of information it contains (Swales, 1990; Salager-Meyer, 1994; Varttala, 2001; Hyland, 1998). The chosen section was precisely read twice word by word in order to identify and locate the hedges. Afterwards, the number of hedges was recorded in each RA and in each language separately. The hedges recorded in the sample, then, classified into the five types of hedges based on Salager-Meyer (1994) taxonomy (equivalents for Farsi articles).

1. Shields, such as can, could, may, might, would, to appear, to seem, probably, to suggest.

2. Approximators of degree, quantity, frequency and time: e.g., approximately, roughly, about, often, occasionally, etc.

3. Authors' personal doubt and direct involvement, expressions such as I believe, to our knowledge, it is our view that ...

4. Emotionally-charged intensifiers, such as extremely difficult/interesting, of particular importance, unexpectedly, surprisingly, etc.

5. Compound hedges, the examples are: could be suggested, would seem likely, would seem somewhat. 


\section{DATA ANALYSIS}

The frequency and types of hedges in Discussion section of Environmental Sciences RAs were categorized, compared and contrasted according to the writers of the articles.

To address the research questions, table 1 presents the frequency and percentage of hedges in English RAs by EWRs and IRWs, and Farsi RAs by IRWs. Tables 2, 3, and 4 indicate whether or not the significant difference exists among these groups in employing hedges in terms of the frequency.

TABLE 1

FREQUENCIES AND PERCENTAGES OF HEDGES IN DISCUSSION SECTION OF ENVIRONMENTAL SCIENCES RAS BY ERWS \& IRWS IN ENGLISH AND FARSI

\begin{tabular}{lllllllllllll}
\hline Hedges types & \multicolumn{1}{c}{ Type 1 } & \multicolumn{3}{c}{ Type 2 } & \multicolumn{2}{c}{ Type 3 } & \multicolumn{1}{c}{ Type 4 } & \multicolumn{2}{c}{ Type 5 } & Total \\
\hline Writers & F. & P. & F. & P. & F. & P. & F. & P. & F. & P. & F. & P. \\
\hline ERWs & 169 & 59.71 & 81 & 28.62 & 9 & 3.18 & 16 & 5.65 & 8 & 2.82 & 283 & 100 \\
IRWs (writing in English) & 110 & 48.67 & 83 & 36.72 & 6 & 2.65 & 15 & 6.63 & 12 & 5.30 & 226 & 100 \\
IRWs (writing in Farsi) & 123 & 61.19 & 67 & 33.33 & 0 & 0 & 5 & 2.5 & 6 & 2.98 & 201 & 100 \\
\hline
\end{tabular}

As table 1 reveals the three groups of writers used type 1 (Shields) hedges as the most frequently ones. English writers employed 169 (59.71\%) hedges while their Iranian counterparts in their English writings employed 110 (48.67\%) hedges and other Iranians in Farsi articles used 123 (61.19\%) out of the total number of 283, 226, and 201 hedges respectively. What table 1 reveals about type 2 (Approximators) hedges is that EWRs employed 81 (28.62\%) out of total, IRWs utilized $83(36.72 \%)$ in English articles, and $67(33.33 \%)$ in Farsi articles out of their total number of hedges. The result of type 3 (Authors' personal doubt and direct involvement) hedges shows that $9(3.18 \%), 6(2.65 \%)$, and 0 hedges of this type used by ERWs, IRWs (English articles), and IRWs (Farsi articles) respectively. The 0 frequency of this type for Farsi RAs may mean that Iranians had no interest to add any personal doubt and have direct involvement in presenting the new information. The frequency of type 4 (Emotionally-charged intensifiers) hedges for ERWs was $16(5.65 \%)$, for IRWs was 15 (6.63\%), and for IRWs when they wrote in Farsi was 5 (2.5\%). Type 5 (compound hedges) hedges' frequency in English texts was $8(2.82 \%)$ for the first group, $12(5.30 \%)$ for the second group, and 6 (2.98\%) for the third group, regarding the total number of hedges for each group. The findings are supported by the chi-square procedure in table 2 to answer the first research question.

TABLE 2

CHI-SQUARE FOR THE FREQUENCY OF HEDGES FOR ENGLISH DISCUSSION SECTIONS WRITTEN BY ERWS AND IRWS

\begin{tabular}{llllll}
\hline Chi-square $=\mathbf{7 . 6 5}$ & \multicolumn{2}{c}{ Degree of freedom $=\mathbf{4}$} & \multicolumn{3}{c}{ Critical chi-square $=\mathbf{9 . 4 9}$} \\
\hline Hedging type & 1 & 2 & 3 & 4 & 5 \\
\hline EWRs & F.169 & F.81 & F.9 & F.16 & F.8 \\
\hline IRWs & F.110 & F.83 & F.6 & F.15 & F.12 \\
\hline
\end{tabular}

Since the chi-square observed value (7.65) at 4 degrees of freedom in Discussion section of English RAs written by ERWs and IRWS is lower than the critical chi-square (9.49), it can be concluded that there is no significant difference between the frequencies of hedges in this two compared groups. It means that the writings of Iranians are influenced by their discipline rather than their own language and culture.

Table 3 is addresses for the second research question of this study through chi-square analysis.

TABLE 3

CHI-SQUARE FOR THE FREQUENCY OF HEDGES FOR ENGLISH AND FARSI DISCUSSION SECTIONS WRITTEN BY ERWS AND IRWS

\begin{tabular}{llllcc}
\hline Chi-square $=\mathbf{1 0 . 0 1}$ & \multicolumn{2}{c}{ Degree of freedom $=\mathbf{4}$} & \multicolumn{3}{c}{ Critical chi-square $=\mathbf{9 . 4 9}$} \\
\hline Hedging type & 1 & 2 & 3 & 4 & 5 \\
\hline ERWs & F.169 & F.81 & F. 9 & F.16 & F.8 \\
\hline IRWs & F.123 & F.67 & F.0 & F.5 & F.6 \\
\hline
\end{tabular}

As can be seen the chi-square value (10.01) at 4 degrees of freedom is higher than the critical chi-square (9.49). Therefore, what is inferred is that there is a significant difference in terms of the frequency of the use of different types of hedges in this analysis. It shows that EWRS employed more hedges than IRWs in their claims. This result indicates that IRWs are more authoritative and direct in their writing in Farsi language and this might be attributed to the nature of their language.

Table 4 provides an answer to the third question which dealts with the frequency of employed hedges by IRWs in their English and Farsi RAs.

TABLE 4

CHI-SQUARE FOR THE FREQUENCY OF HEDGES FOR ENGLISH AND FARSI DISCUSSION SECTIONS WRITTEN BY IRWS

\begin{tabular}{lccccc}
\hline Chi-square $=\mathbf{1 4 . 0 2}$ & \multicolumn{2}{c}{ Degree of freedom $=\mathbf{4}$} & \multicolumn{2}{c}{ Critical chi-square= 9.49 } \\
\hline Hedging type & 1 & 2 & 3 & 4 & 5 \\
\hline IRWs (writing in English) & F.110 & F.83 & F.6 & F.15 & F.12 \\
\hline IRWs (writing in Farsi) & F.123 & F.67 & F.0 & F.5 & F.6 \\
\hline
\end{tabular}


Again as this table demonstrates the observed value of the chi-square (14.02) at 4 degrees of freedom is higher than the critical chi-square (9.49), it can be concluded that there is a significant difference between the writings of the Iranians in English and Farsi in the field of Environmental Sciences. What this finding suggests is that expressing certainty is important in Farsi language. Therefore, the hedged texts are considered as the less reliable ones in Environmental Sciences discipline when the authors write in Farsi.

\section{DISCUSSION}

The data analysis revealed that all research writers used type 1 (Shields) hedges as the most frequent ones. This finding is supported by the findings of Salager-Meyer (1994), Selinker (1979), Adam-Smith (1984), and Trimble (1985) who stated that the most frequently used hedging device in articles was shield category. Based on the first comparison, both ERWs and IRWs employed hedges almost equally in English RAs. It means that both groups of writers had the same attitude towards using hedging in this discipline while writing in English. This finding is concurrent with the findings of the previous studies, such as Winardi's (2009) and Mohammadi Khahan (2006) which showed that the equality in using hedges between native and non-native researchers seems to be related the fact that writers are more influenced by their discipline than their nationality.

In the second comparison, we found that type 3 (Authors' personal doubt and direct involvement) hedges have not been employed by Iranian writers in Farsi articles. This might be related to the nature of their language, i.e. Farsi, which may not let authors to reveal thier personal doubts and get involved directly in the issue which can stem from their culture. The other reason for this, is possibly related to the convention exists in environmental discipline in Farsi language. Namely, fewer hedges usually represent a higher acceptability of the articles in this discipline in Farsi language. Therefore, significant differences were found in the frequency of hedges in two languages by different authors. This finding can be supported by the findings of Vassileva (2001) and Yang (2003) who found that nonEnglish research articles by their native speakers included fewer hedges than English research articles written by native speakers of English.

The third comparison between English and Farsi texts written by IRWs indicated that English texts enjoyed more hedges than Farsi texts. The difference of the frequency of hedges in two languages was significant. It seems that Iranian writers tend to be more direct in tone when they write in Farsi language. This direct tone might be attributed to the norms and conventions which govern the Environmental Sciences discipline in Farsi language. This finding is in line with Jalilifar (2011) who found that Iranian writers employed fewer hedges when they wrote in their own language than when they wrote in English.

Iranian writers' direct tone in Farsi language can be seen by the number of hedges and hedging statements which are fewer than those in English articles by English and Iranian writers. Academic English uses more hedges and fewer boosters, which means that English writers are more tactful and cautious in uttering their claims and they tend to address their readers indirectly; but Iranian writers seem to be less conservative and instead address their readers directly (Jalilifar, 2011). Jalilifar (2011) believes that the differences between Farsi and English writings in utilizing hedges might stem from the insufficient awareness of IRWs of the role of hedges and the fact that they do not usually receive explicit instruction on how to use them in Farsi academic context. A writer may use a hedge, not only to express doubt and reduce personal commitment for a statement but also to gain acceptance from the community for which he writes but reducing the force of the statements on the addresses. Iranian writers' less use of hedges in Farsi RAs might indicate that they are so certain about their results that they leave little doubt on them.

In addition to this reason which has been announced by Jalilifar (2011), it seems that another interpretation may exist. It is assumed that if researchers wish to go through the academic gateway and enter the community in Environmental Sciences discipline in Farsi language they should show their certainty about their findings, since the uncertain claims are frowned upon and not considered as the membership characteristic.

Culture can affect the style of writing as well. As Wishnoff (2000) states culture is significant in defining what we say, and how, where, and when we say it and therefore influences and shapes language and reflects by it (Deng, 2003). Iranian writers with a different cultural background from English writers may have their own understanding of appropriate formality, directness, politeness and other pragmatic rules. Hence, academic writing which the Iranian writers take in their own language seems to be purely content-based and impersonal at the same time. This kind of certainty in Farsi language seems to be in the opposite way of negative politeness. Despite the fact that IRWs observe the rules of the discipline while they write in Farsi, they leave little room for their addressees and from the international perspective of the politeness, they seem to invade the addressees' territories and threaten their negative face.

\section{CONCLUSION}

The analysis of the corpus of the present study showed that ERWs, IRWs write in English, and IRWs who write in Farsi used all types of hedges in their writings except type 3 (Authors' personal doubt and direct involvement) hedges which have not been observed in Farsi written texts. All three groups of writers used type 1 (Shields) hedges as the most frequent ones followed by type 2 (Approximators) hedges. Utilizing chi-square procedure revealed no statistically significant difference in the frequency of hedges in English Environmental Sciences RAs' Discussion sections written 
by ERWs and IRWS. This fact might be related to their disciplinary backgrounds. However, by comparing ERWs' English texts with IRWs' Farsi ones and both groups of IRWs' writings with together, we realized that hedges were used more when authors wrote in English. Therefore, significant difference was found in the frequency of hedges between English texts and Farsi ones. The difference can be attributed to the writers' different cultural and linguistic backgrounds such as values, conventions, beliefs and attitudes.

The results of our study give further support to Salager-Meyer, Alcaraz Ariza, and Zambrano's (2003) claim who asserted that research reporting is cultural/language bound and that courtesy markers, solidarity and tactfulness are cultural manifestations. They are also in line with the claim that different cultures vary in their discourse preferences (Valero-Garces, 1996). This study revealed that the educational systems are not static but are dynamic and can be changed under the influence from other educational systems (Salager-Meyer, 1994).

Therefore, it can be concluded that one cannot communicate properly with people in other communities unless he has enough knowledge of the conventions of presenting and organizing ideas in those communities. Hedges provide a part of this knowledge for us.

As a pedagogical implication, this study revealed the importance of increasing students' awareness of the way native speakers of English organize their writings. English as the dominant language of scientific and academic writing in the world provides a ground for its writers to follow scientific and academic writing conventions. Therefore, familiarizing students with the rule and norms of academic writing might help them develop their understanding of hedges in their own academic discourse community.

Furthermore, the results of this study can be of special value for Iranian Environmental Sciences researchers who want to publish their writings in international journals. Observing the conventions in their RAs would make them be accepted in global community. The findings of the paper also might help ESP (English for Specific Purposes) and EAP (English for Academic Purposes) instructors to raise students' awareness about using hedges appropriately.

Considering the importance of hedging devices in academic writing, prospective researchers focus on the other sections of the Environmental Sciences RAs. The present study examined only the RAs in Environmental Sciences field. It is suggested that further researches explore how Iranian writers from different disciplines differ from their nativeEnglish counterparts in utilizing hedges in their academic writings. Such studies would definitely shed light on the relationships between language and culture.

\section{REFERENCES}

[1] Adams Smith, D. (1984). Medical discourse: Aspects of author's comment. English for Specific Purposes, 3, 25-36.

[2] Atai, M. R. \& Sadr, L. (2008). A cross-cultural study of hedging devices in discussion section of applied linguistics research articles. Journal Teaching English Language and Literature Society of Iran, 7(2), 1-22.

[3] Brown, P. \& Levinson, S. (1978). Politeness: Some universals in language usage. Cambridge: Cambridge University Press

[4] Brown, P. \& Levinson, S. (1987). Politeness: Some universals in language usage. Cambridge: Cambridge University Press.

[5] Crismore, A. (1984). The rhetoric of textbooks: Metadiscourse. Journal of Curriculum Studies, 16(3), $279-296$.

[6] Crismore, A., Markkanen, R. \& Steffensen, M. (1993). Metadiscourse in persuasive writing. A study of texts written by American and Finnish University students. Written Communication, 10(1), 39-71.

[7] Crompton, P. (1997). Hedging in academic writing: some theoretical problems. English for Specific Purposes, 16(4), $271-287$.

[8] Deng, Y. (2003). Language and Culture. Beijing: Foreign Language Teaching and Research Press.

[9] Falahati, R. (2004). A Contrastive Study of Hedging in English and Farsi Academic Discourse. Unpublished MA thesis. Tehran: University of Tehran, Department of Linguistics.

[10] Hyland, K. (1995). The author in the text: Hedging in scientific writing. Hong Kong Papers in Linguistics and Language Teaching, 18, 33-42.

[11] Hyland, K. (1996). Writing without conviction? Hedging in science research articles. Applied Linguistics, 17(4), $433-453$.

[12] Hyland, K. (1998). Persuasion and context: The pragmatics of academic metadiscourse. Journal of Pragmatics, $30,437-455$.

[13] Hyland, K. (1999). Academic attribution: Citation and the construction of disciplinary knowledge. Applied Linguistics, 20(3), 341-267.

[14] Hyland, K. (2000). Disciplinary Discourses: Social interactions in academic writing. London: Longman.

[15] Hyland, K. (2004). Disciplinary interactions: Metadiscourse in L2 postgraduate writing. Journal of Second Language Writing, 13(2), 133-151.

[16] Jalilifar, A. R. (2011). World of attitudes in research article discussion sections: A cross-linguistic perspective. Journal of Technology and Education, 5(3), 177-186.

[17] Kreutz, H. \& Harres, A. (1997). Some Observations on the Distribution and Function of Hedging in German and English Academic Writing. Culture and Styles of Academic Discourse, Mouton de Gruyter, Berlin.

[18] Longman dictionary of contemporary English: The living dictionary (2006). Harlow: Pearson Education Limited.

[19] Martin, M. P. (2008). The mitigation of scientific claims in research papers: A comparative study. International Journal of English Studies, 8(20), 133-152.

[20] Mauranen, A. (1992). Cultural differences in academic rhetoric: A textlinguistic Study. Unpublished PhD thesis. Birmingham: University of Birmingham.

[21] Mauranen, A. (1993). Contrastive ESP rhetoric: Metatext in Finnish-English economics texts. English for Specific Purposes, 12, $3-22$. 
[22] Mohammadi Khahan, F. (2006). A contrastive analysis of the frequency and types of hedges and boosters used in results and discussion sections of medical and applied linguistics research articles written by PNS and ENS researchers. Unpublished MA thesis. Tehran: University of Teacher Education, Department of Foreign Languages.

[23] Myers, G. (1989). The pragmatics of politeness in scientific articles. Applied Linguistics, 10(1), 1-35.

[24] Namsarayev, V. (1997). Hedging in Russian academic writing in sociological texts. Hedging and discourse: Approaches to the analysis of a pragmatic phenomenon in academic texts. Berlin: Mouton de Gruyter.

[25] Nikula, T. (1997). Interlanguage view on hedging. In R. Markkanen \& R. Schröder (Eds.), Hedging and discourse approaches to the analysis of a pragmatic phenomenon in academic texts (pp. 188-207). Berlin \& New York: Walter de Gruyter.

[26] Salager-Meyer, F. (1994). Hedges and textual communicative function in medical English written discourse. English for Specific Purposes, 13(2), 149-170.

[27] Salager-Meyer, F. (1997). I think that perhaps you should: A study of hedges in written scientific discourse. In T. Miller (Ed.), Functional approaches to written text: Classroom applications. Washington, D.C: United States Information Agency.

[28] Salager-Meyer, F., Defives, G. \& Hamelynck, M. (1996). Epistemic modality in 19th and 20th century medical English written discourse: A principal component analysis, interface. Journal of Applied Linguistics, 10(2), 163-199.

[29] Salager-Meyer, F., Alcaraz Ariza, M. A. \& Zambrano, N. (2003). The scimitar, the dagger and the glove: Intercultural differences in the rhetoric of criticism in Spanish, French and English medical discourse (1930-1995). English for Specific Purposes, 22, 223-247.

[30] Swales, J. M. (1990). Genre Analysis: English in academic and research settings. Cambridge: Cambridge University Press.

[31] Trimble, L. (1985). English for science and technology: A discourse approach. Cambridge: Cambridge University Press.

[32] Valero-Garces, C. (1996). Contrastive ESP rhetoric: Metatext in Spanish-English economics texts. English for Specific Purposes, 15(4), 279-294.

[33] Vande Kopple, W. J. (1985). Some exploratory discourse on metadiscourse. College Composition and Communication, 36(1), 82-93.

[34] Vande Kopple, W. J. (2002). Metadiscourse, discourse, and issues in composition and rhetoric. In E. Barton \& G. Stygall (Eds.), Discourse studies in composition (pp. 91-114). Gresskill, NJ: Hampton Press, Inc.

[35] Varttala, T. A. (2001). Hedging in scientifically oriented discourse: Exploring variation according to discipline and intended audience. Unpublished Ph. D dissertation. Finland: University of Tampereen Yliopisto.

[36] Vassileva, I. (2001). Commitment and detachment in English and Bulgarian academic writing. English for Specific Purposes, 20, 83-102.

[37] Widdowson, H. G. (1984). Explorations in applied linguistics. Oxford: Oxford University Press.

[38] Williams, J. M. (1981). Style: Ten lessons in clarity and grace. New York: Harper Collins Publishers.

[39] Winardi, A. (2009). The use of hedging devices by American and Chinese writers in the field of applied linguistics. Sastra Inggris Journal, 8(3), 228-237.

[40] Wishnoff, J., R. (2000). Hedging your bets: L2 learners' acquisition of pragmatic devices in academic writing and computermediated discourse. Second Language Studies, 19(1), 119-148.

[41] Yang, H. (2006). A comparative study of scientific hedging by Chinese writers and English writers. Language Education papers, 3(3), 58-62.

[42] Yang, Y. (2003). A contrastive study of hedges in English and Chinese academic discourse. Unpublished MA thesis. China: Changchun, Jilin University.

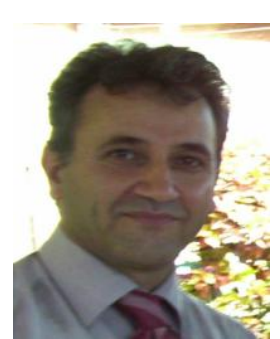

Alireza Bonyadi was born in 1964 in Urmia, Iran. In March, 2011, he earned his PhD in Teaching English as a Second Language from faculty of education university of Malaya, Kualalumpur, Malaysia. Presently he is the Head of English Department at Science and Research Branch of IAU, Azarbaijan-e-gharbi. He has published several research papers in scholastic journals some of them have been listed below: • (2003) Translation: Back from Siberia. Translation Journal. Vol.7, No. 3, July. • (2010) The Rhetorical properties of Schematic structures of Newspaper Editorials: A comparative study of English and Persian editorials. Discourse and Communication. - (2011) Linguistic nature of presupposition in newspaper editorials. International Journal of Linguistics Vol. 3, No. 1.

His research interests include Discourse Analysis, Translation Studies and Language Teaching methodology. Dr. Bonyadi is presently an academic member of faculty of humanities in IAU, Urmia, Iran

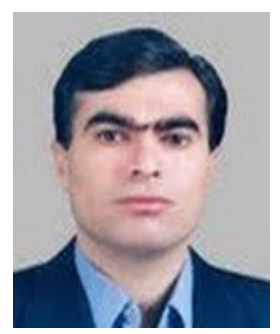

Javad Gholami received his PhD in Teaching English to Speakers of Other Languages (TESOL) from Tabriz University in 2007. He received his B.A. from Tehran University for Teacher Education and M.A. from Tehran University. He has published several research papers in scholastic journals some of them have been listed below: - (2007) Reactive and Preemptive Language Related Episodes and Uptake in an EFL Class. Asian EFL Journal. • (2011) Interviewers' Gender and Interview Topic in Oral Exams. Theory and Practice in Language Studies. Dr. Gholami's research interests include focus on form and learner uptake in EFL settings, and material development in English for Academic Purposes. 


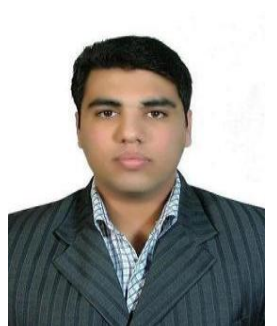

Sina Nasiri received his M.A. in TEFL in 2011. He is interested in the researches which result in better understanding of the nature of writing by native speakers of English in academic community. These may provide non-native researchers to adapt themselves with the context of English communities in academic world. $\mathrm{He}$ is also interested in the evaluation of EFL materials. Some samples of his works have been listed below: - (2011) Textbook Evaluation: A Retrospective Study. Journal of Academic and Applied Studies, 1(5), 9-17. (With Ahmadi). • (2012) Hedging Devices by Native and Non-Native Psychology Researchers. International Journal on New Trends in Education and Their Implications, 3(2), 151-154.

His research interests cover the areas of genre and genre analysis, contrastive rhetoric, cross-cultural differences, and material evaluation.

This article has been fully extracted from Sina Nasiri MA thesis. 